\title{
Pearls \& Oy-sters: Bow hunter syndrome: A rare cause of posterior circulation stroke
}

\section{Do not look the other way}

Neville Jadeja, MD, MPH, and Krishna Nalleballe, MD

Neurology ${ }^{\circledR}$ 2018;91:329-331. doi:10.1212/WNL.0000000000006009
Correspondence

Dr. Jadeja

drnevillejadeja@gmail.com

\section{Pearls}

- Bow hunter syndrome (BHS) is an uncommon cause of vertebrobasilar insufficiency that results from occlusion or injury to the vertebral artery (VA) during neck rotation.

- The cause is often a bony abnormality that may compress the VA compromising distal flow or lead to vessel wall injury resulting in thromboembolism.

\section{Oy-sters}

- Posterior circulation strokes in young individuals should alert the neurologist to suspect BHS, especially if high cervical spine abnormalities are detected on initial head imaging.

- Dynamic occlusion of the VA may not be evident on angiography if a thromboembolic mechanism such as a pseudoaneurysm is involved.

A 24-year-old man with no relevant medical history presented to our institution with a week of intermittent dizziness exacerbated by turning his head to the left. He acutely developed diplopia and disorientation on the day of presentation to the emergency room. He reported similar complaints a month prior. There was no history of fevers, rashes, headache, or neck trauma. There was no family history of similar complaints, vascular or connective tissue diseases, strokelike episodes, seizures, or early-onset dementia. Examination demonstrated mild impairment of cognition and a right hemiparesis. Initial head $\mathrm{CT}$ revealed congenital atlas nonunion (C1) with fusion of the second and third vertebral bodies (C2-C3). Brain MRI revealed diffusion restriction in the left thalamus and bilateral dorsal midbrain indicative of multiple acute infarctions. Chronic infarctions were also present in the right cerebellum, which indicated prior episodes of ischemia. A series of dynamic X-rays showed malalignment of the lateral masses of the atlas with $\mathrm{C} 2$, but there was no evidence of instability. CT angiography (CTA) revealed the presence of a pseudoaneurysm of the right VA at its exit from the $\mathrm{C} 2$ transverse foramen. This was suspected to be the source of the posterior circulation emboli. Left VA was unremarkable. There was no evidence of VA dissection on CTA (figure). Magnetic resonance angiography (MRA) with fat-suppressed images of the neck was not performed. The rest of the workup including complete blood count, serum chemistry and lipids profile, glycosylated hemoglobin levels, liver function tests, hypercoagulability studies, D-dimer levels, transthoracic echocardiography, and short-term Holter monitoring were unremarkable. A transesophageal echocardiogram was not performed because of concerns for further neck manipulation.

A clinical diagnosis of BHS was made. Aspirin was initiated for secondary stroke prevention and the patient was referred for an evaluation for corrective cervical spinal surgery. Approximately 1 week later, the patient returned to an outside hospital with new cerebellar infarcts. Digital subtraction angiography (DSA) confirmed a right VA pseudoaneurysm that was suspected to have been caused by repetitive mechanical injury to the right VA from his congenital cervical spinal abnormalities during neck rotation. Dynamic occlusion of the VAs could not be reproduced 

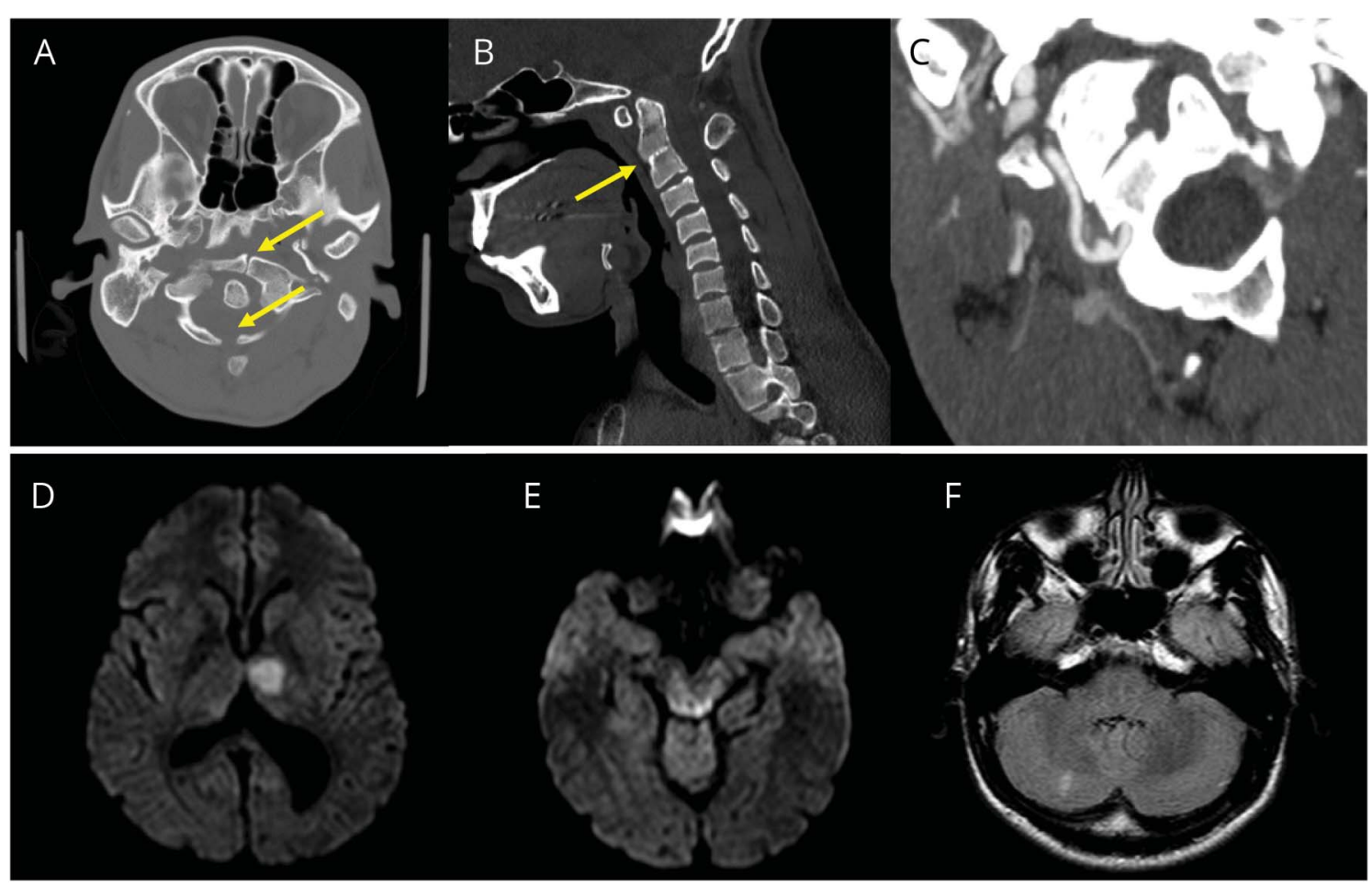

(A) CT cervical spine shows nonunion of C1 vertebrae (arrow). (B) CT cervical spine shows fusion of C2-3 vertebral bodies (arrow). (C) CT angiogram of the neck shows a right vertebral artery pseudoaneurysm as it exits the C2 transverse foramina. (D) Diffusion-weighted MRI shows acute left thalamic infarction. (E) Diffusion-weighted MRI shows acute dorsal midbrain infarctions. (F) Fluid-attenuated inversion recovery MRI shows chronic right cerebellar infarctions.

during angiogram and spinal surgery was deferred. He is being managed conservatively with aspirin and neck immobilization without recurrence at 3 months follow-up.

\section{Discussion}

Sorensen ${ }^{1}$ coined the term "bow hunter syndrome" in 1978 to describe a case of rotational VA compression causing ischemic brainstem stroke. The dominant VA is frequently compressed, and collateral flow is limited in the presence of predisposing factors such as congenital atresia, hypoplasia, fenestration, or stenosis of the contralateral VA, though this was not evident in our patient. ${ }^{2-4}$ Prior studies have also shown the left VA to be more commonly involved than the right. This is because left VA dominance is seen in about half the population and its involvement is more likely to be symptomatic. ${ }^{5,6}$ Osteophytes or bone spurs were found to be the commonest underlying etiology of VA compression in one systematic review of 142 reported adult cases of BHS. ${ }^{5}$ Other reported atraumatic etiologies include congenital abnormalities such as fibrous bands tethering the VA or atlantoaxial bony anomalies, atlanto-axial instability, cervical disc herniation, cervical spondylosis, and rheumatoid arthritis. ${ }^{7-13}$ Isolated case reports also exist of BHS after surgical correction of subclavian aneurysms or VA sacrifice. ${ }^{5,14}$ The ischemic mechanism may not always be hemodynamic; rarely, it may be thromboembolic, as demonstrated in our patient. It has been postulated that repeated neck rotation and VA compression against bony or fibrous structures may injure the vessel wall, leading to thrombosis and infarction either due to direct injury to the intimal lining or through local complications such as dissection, perforation, and pseudoaneurysm formation and subsequent distal embolization. ${ }^{15}$ The VA can be compressed at all vertebral levels, but it is most common in the high cervical spine, C1-2 being the most common site. ${ }^{5}$ The VAs as they ascend superiorly pass through the foramina transversarium of 6 cervical vertebrae and atlas, they then exit travelling posteriorly and medially over the superior articular processes to penetrate the atlanto-occipital ligament and enter the skull through the foramen magnum. The atlanto-occipital joint is a major site for neck rotation and the VA is relatively immobilized at its exit from the $\mathrm{C} 1$ transverse process and its entry into the atlanto-occipital ligament; this anatomical relationship makes the VA prone to occlusion or injury at this site. Congenital cervical abnormalities are also more prevalent at this level and increase the likelihood of rotational injury. ${ }^{15}$ Of note, vascular injury from bony elements is not unique to the vertebrobasilar circulation and may occur in the carotid circulation. Previous studies have suggested an association with cervical carotid dissections and increased styloid process length. ${ }^{16}$ Typically, patients present with presyncope, syncope, vertigo, diplopia, and horizontal nystagmus directed towards the side of the compressed vessel. The ischemic 
symptoms are frequently transient; however, irreversible deficits including medullary and cerebellar infarctions have also been described. ${ }^{17}$ The direction of head rotation does not reliably predict the side of vessel compression. ${ }^{18}$ The condition may be demonstrated on vascular ultrasound, CTA, or MRA. DSA is the preferred method of diagnosis. ${ }^{18}$ In one series, half of those determined to have BHS did not show evidence of dynamic occlusion on ultrasound, though this was the most commonly used preoperative imaging modality. ${ }^{18}$ Angiography provides precise localization of the flow limiting lesion, allows assessment of collateral flow, and confirms the presence of dynamic occlusion or compression..$^{5}$ Occasionally there can be more than one compressive site. ${ }^{19}$ In those cases where dynamic occlusion cannot be demonstrated, potential thromboembolic mechanisms (nonocclusive) such as pseudoaneurysm formation, thrombosis, or dissection should be sought. ${ }^{15} \mathrm{CTA}$ may be equal or superior to MRA with fat suppression imaging of the neck to detect a VA dissection. ${ }^{20,21}$ A detailed history and physical examination is essential to exclude other alternative diagnoses that may lead to posterior circulation ischemia. Common mimics include VA dissection; vasculitis; reversible cerebral vasoconstriction syndrome; mitochondrial encephalopathy, lactic acidosis, and stroke-like episodes; and subclavian steal phenomenon or cardiac or paradoxical embolism. ${ }^{22}$

BHS is a rare disorder and its management has not been standardized, but it is most often surgical..$^{5}$ An initial conservative approach may include neck immobilization using a cervical collar or neck brace. In addition, the patient should be instructed to avoid rotating the neck in the symptomatic direction. ${ }^{17}$ Both antiplatelets and anticoagulation have been used for secondary stroke prevention in cases of BHS. ${ }^{17} \mathrm{~A}$ previous randomized clinical trial of 250 patients comparing antiplatelet agents with anticoagulation in cases of extracranial carotid and vertebral dissection concluded that there was no difference in efficacy between the 2 groups in terms of secondary stroke prevention and death. ${ }^{23}$ Other authorities have suggested benefit from anticoagulation during the acute period of cervical or vertebral dissections as most strokes happen within a 7-day period after brain ischemia. ${ }^{23,24}$ However, it is not clear if these results are applicable to all cases of ischemic stroke due to BHS as evidence of vascular injury (i.e., dissections or pseudoaneurysms) may not be evident. Surgical correction can be potentially curative. Frequently used procedures include surgical decompression of the VA or corrective fusion of $\mathrm{C} 1-2 .{ }^{18}$ More recently, success with endovascular stenting of VAs or coil embolization of a symptomatic nondominant VA have also been reported (with patent dominant VA). ${ }^{4,25,26}$ Management must be individualized, based on the underlying mechanism of vascular compression and injury.

\section{Author contributions}

Neville Jadeja: manuscript preparation. Krishna Nalleballe: manuscript supervision and critical revision for intellectual content.

\section{Acknowledgment}

Shilpa Deshmukh (Lincoln Medical and Mental Health Center) edited the manuscript for nonintellectual content.

\section{Study funding}

No targeted funding reported.

\section{Disclosure}

The authors report no disclosures relevant to the manuscript. Go to Neurology.org/N for full disclosures.

\section{References}

1. Sorensen BF. Bow hunter's stroke. Neurosurgery 1978;2:259-261.

2. Chen JJ, Chung MH, Yang CH, Chen DL. Vertebrobasilar artery anomaly presenting with transient bow hunter's syndrome. Tzu Chi Med J 2010;22:149-152.

3. Yamaguchi S, Horie N, Tsunoda K, et al. Bow hunter's stroke due to stretching of the vertebral artery fenestration: a case report. NMC Case Rep J 2015;2:9-11.

4. Darkhabani MZ, Thompson MC, Lazzaro MA, Taqi MA, Zaidat OO. Vertebral artery stenting for the treatment of bow hunter's syndrome: report of 4 cases. J Stroke Cerebrovasc Dis 2012;21:908.e1-908.e5.

5. Rastogi V, Rawls A, Moore O, et al. Rare etiology of bow hunter's syndrome and systematic review of literature. J Vasc Interv Neurol 2015;8:7.

6. Cloud GC, Markus HS. Diagnosis and management of vertebral artery stenosis. QJM 2003;96:27-54.

7. Mapstone T, Spetzler RF. Vertebrobasilar insufficiency secondary to vertebral artery occlusion from a fibrous band: case report. J Neurosurg 1982;56:581-583.

8. Matsuyama T, Morimoto T, Sakaki T. Bow hunter's stroke caused by a nondominant vertebral artery occlusion: case report. Neurosurgery 1997;41:1393-1395.

9. Chough CK, Cheng BC, Welch WC, Park CK. Bow hunter's stroke caused by a severe facet hypertrophy of C1-2. J Korean Neurosurg Soc 2010;47:134-136.

10. Go G, Hwang SH, Park IS, Park H. Rotational vertebral artery compression: Bow Hunter's syndrome. J Korean Neurosurg Soc 2013;54:243-245.

11. Vates GE, Wang KC, Bonovich D, Dowd CF, Lawton MT. Bow hunter stroke caused by cervical disc herniation: case report. J Neurosurg Spine 2002;96:90-93.

12. Bakay L, Leslie EV. Surgical treatment of vertebral artery insufficiency caused by cervical spondylosis. J Neurosurg 1965;23:596-602.

13. Robinson BP, Seeger JF, Zak SM. Rheumatoid arthritis and positional vertebrobasilar insufficiency: case report. J Neurosurg 1986;65:111-114.

14. Ikeda DS, Villelli N, Shaw A, Powers C. Bow hunter's syndrome unmasked after contralateral vertebral artery sacrifice for aneurysmal subarachnoid hemorrhage. J Clin Neurosci 2014;21:1044-1046.

15. Sherman DG, Hart RG, Easton JD. Abrupt change in head position and cerebral infarction. Stroke 1981;12:2-6.

16. Raser JM, Mullen MT, Kasner SE, Cucchiara BL, Messe SR. Cervical carotid artery dissection is associated with styloid process length. Neurology 2011;77: 2061-2066.

17. Duan G, Xu J, Shi J, Cao Y. Advances in the pathogenesis, diagnosis and treatment of bow hunter's syndrome: a comprehensive review of the literature. Interv Neurol 2016; 5:29-38.

18. Zaidi HA, Albuquerque FC, Chowdhry SA, Zabramski JM, Ducruet AF, Spetzler RF. Diagnosis and management of bow hunter's syndrome: 15 -year experience at barrow neurological institute. World Neurosurg 2014;82:733-738.

19. Kuether TA, Nesbit GM, Clark WM, Barnwell SL. Rotational vertebral artery occlusion: a mechanism of vertebrobasilar insufficiency. Neurosurgery 1997;41: 427-433.

20. Vertinsky AT, Schwartz NE, Fischbein NJ, Rosenberg J, Albers GW, Zaharchuk G. Comparison of multidetector CT angiography and MR imaging of cervical artery dissection. Am J Neuroradiol 2008;29:1753-1760.

21. Levy C, Laissy JP, Raveau V, et al. Carotid and vertebral artery dissections: threedimensional time-of-flight MR angiography and MR imaging versus conventional angiography. Radiology 1994;190:97-103.

22. Nouh A, Remke J, Ruland S. Ischemic posterior circulation stroke: a review of anatomy, clinical presentations, diagnosis, and current management. Front Neurol 2014;5:30.

23. CADISS Trial Investigators. Antiplatelet treatment compared with anticoagulation treatment for cervical artery dissection (CADISS): a randomized trial. Lancet Neurol 2015;14:361-367.

24. Biousse V, D’Anglejan-Chatillon J, Touboul PJ, Amarenco P, Bousser MG. Time course of symptoms in extracranial carotid artery dissections: a series of 80 patients. Stroke 1995;26:235-239.

25. Schievink WI. The treatment of spontaneous carotid and vertebral artery dissections. Curr Opin Cardiol 2000;15:316-321.

26. Thomas B, Barreau X, Pointillart V, Sibon I, Renou P. Endovascular embolization of a nondominant vertebral artery compressed by an osteophyte to prevent recurrence of vertebrobasilar infarctions. J Stroke Cerebrovasc Dis 2015;24:e257-e259. 


\section{Neurology}

Pearls \& Oy-sters: Bow hunter syndrome: A rare cause of posterior circulation stroke: Do not look the other way

Neville Jadeja and Krishna Nalleballe

Neurology 2018;91;329-331

DOI 10.1212/WNL.0000000000006009

This information is current as of August 13, 2018

\section{Updated Information \&} Services

References

Citations

Subspecialty Collections

Permissions \& Licensing

Reprints including high resolution figures, can be found at: http://n.neurology.org/content/91/7/329.full

This article cites 26 articles, 4 of which you can access for free at: http://n.neurology.org/content/91/7/329.full\#ref-list-1

This article has been cited by 1 HighWire-hosted articles: http://n.neurology.org/content/91/7/329.full\#\#otherarticles

This article, along with others on similar topics, appears in the following collection(s):

All Cerebrovascular disease/Stroke

http://n.neurology.org/cgi/collection/all_cerebrovascular_disease_strok e

Information about reproducing this article in parts (figures,tables) or in its entirety can be found online at:

http://www.neurology.org/about/about_the_journal\#permissions

Information about ordering reprints can be found online:

http://n.neurology.org/subscribers/advertise

Neurology ${ }^{\circledR}$ is the official journal of the American Academy of Neurology. Published continuously since 1951, it is now a weekly with 48 issues per year. Copyright @ 2018 American Academy of Neurology. All rights reserved. Print ISSN: 0028-3878. Online ISSN: 1526-632X.



